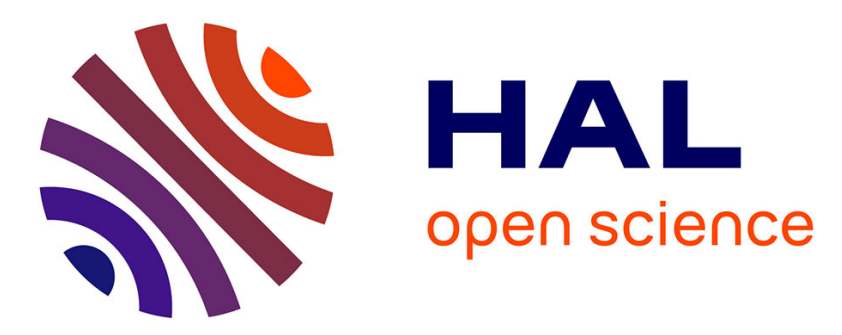

\title{
Dielectric properties of tetragonal tungsten bronze films deposited by RF magnetron sputtering
}

\author{
Romain Bodeux, Dominique Michau, Michaël Josse, Mario Maglione
}

\section{To cite this version:}

Romain Bodeux, Dominique Michau, Michaël Josse, Mario Maglione. Dielectric properties of tetragonal tungsten bronze films deposited by RF magnetron sputtering. Solid State Sciences, 2014, 38, pp.112-118. 10.1016/j.solidstatesciences.2014.10.007 . hal-01078544

\section{HAL Id: hal-01078544 \\ https://hal.science/hal-01078544}

Submitted on 31 Oct 2014

HAL is a multi-disciplinary open access archive for the deposit and dissemination of scientific research documents, whether they are published or not. The documents may come from teaching and research institutions in France or abroad, or from public or private research centers.
L'archive ouverte pluridisciplinaire $\mathbf{H A L}$, est destinée au dépôt et à la diffusion de documents scientifiques de niveau recherche, publiés ou non, émanant des établissements d'enseignement et de recherche français ou étrangers, des laboratoires publics ou privés. 


\title{
Dielectric properties of tetragonal tungsten bronze films deposited by RF magnetron sputtering
}

Romain Bodeux, Dominique Michau, Michaël Josse and Mario Maglione

ICMCB-CNRS, Université de Bordeaux, 87 avenue du Dr. A. Schweitzer, Pessac F-33608, France

E-mail: d.michau@icmcb-bordeaux.cnrs.fr

\begin{abstract}
Tetragonal tungsten bronze (TTB) films have been synthesised on $\operatorname{Pt}(111) / \mathrm{TiO}_{2} / \mathrm{SiO}_{2} / \mathrm{Si}$ substrates from $\mathrm{Ba}_{2} \mathrm{LnFeNb}_{4} \mathrm{O}_{15}$ ceramics ( $\mathrm{Ln}=\mathrm{La}, \mathrm{Nd}, \mathrm{Eu}$ ) by $\mathrm{RF}$ magnetron sputtering. X-ray diffraction measurements evidenced the multi-oriented nature of films with some degrees of preferential orientation along (111). The dependence of the dielectric properties on temperature and frequency has been investigated. The dielectric properties of the films are similar to those of the bulk, i.e., $\varepsilon \sim 150$ and $\sigma \sim 10^{-6} \Omega^{-1} \mathrm{~cm}^{-1}$ at $1 \mathrm{MHz}$ and room temperature. The films exhibit two dielectric anomalies which are attributed to Maxwell Wagner polarization mechanism and relaxor behaviour. Both anomalies are sensitive to post-annealing under oxygen atmosphere and their activation energies are similar $\mathrm{E}_{\mathrm{a}} \sim 0.30 \mathrm{eV}$. They are explained in terms of electrically heterogeneous contributions in the films.
\end{abstract}

Keywords: TTB, PVD, semiconductor oxide, interfaces, Schottky barrier, ferroelectric 


\section{Introduction}

In the search for improved electronic functionalities, perovskite oxides with the formula $\mathrm{ABO}_{3}$ are widely studied because of their versatile properties allowing for many applications. Chemical substitution allows for the tuning of their physical properties like magnetization and polarization [1]. Thus, perovskites could be compatible with the development of a new generation of Random Access Memories (RAMs), in which the superposition and coupling of ferromagnetism and ferroelectricity would be used. Such materials, simultaneously exhibiting these two properties, are known as multiferroics. One can achieve multiferroism in perovskites by inducing a structural distortion and polarization with appropriate substitution at the A site, while magnetism is induced from the B site cations, as in $\mathrm{BiMnO}_{3}$ [2]. However such multiferroic perovskites are rare, and it is important to investigate others materials families, particularly by relying on an increased range of cationic substitutions.

In this view, tetragonal tungsten bronzes (TTB) are particularly attractive, because of the diversity of cationic sites they offer. Their general formula is $(\mathrm{A} 1)_{4}(\mathrm{~A} 2)_{2}(\mathrm{C})_{4}(\mathrm{~B} 1)_{2}(\mathrm{~B} 2)_{8} \mathrm{O}_{30}$, and their polyhedral linking can be related to the perovskite structure, through appropriate rotations of "perovskite columns" [3]. The TTB structure is a framework of edge-sharing $\mathrm{BO}_{6}$ octahedra in which three types of interstices (A1, A2 and C) are occupied by a variety of cations. Those in A1 occupy a pentagonal channel while those in A2 occupy a square channel. Generally, the smallest interstices (C) are empty. The most studied TTB-type systems are $\mathrm{Ba}_{2} \mathrm{NaNb}_{5} \mathrm{O}_{15}$ (BNN) [4,5] and $\mathrm{Sr}_{1-\mathrm{x}} \mathrm{Ba}_{\mathrm{x}} \mathrm{Nb}_{2} \mathrm{O}_{6}$ (SBN) [6], which are candidates for the development of optoelectronic devices. In addition they show remarkable ferroelectric properties such as spontaneous polarization $\mathrm{P}_{\mathrm{S}} \sim 40 \mu \mathrm{C} / \mathrm{cm}^{2}$ at room temperature. TTB compounds were also prepared by inserting trivalent rare earth ions [7-10]. Their dielectric behaviour is rather complex, indicating a large flexibility of their physical properties upon chemical substitution, and is related to subtle structural modifications. For example, it was reported that the ferroelectric/relaxor behaviour of $\mathrm{Ba}_{2} \mathrm{LnNb}_{3} \mathrm{Ti}_{2} \mathrm{O}_{15}(\mathrm{Ln}=$ rare earth $)$ is driven by the size of barium and rare earth ions [11,12]. The compounds with a larger size difference between the cations occupying A1 and A2 tends to be normal ferroelectric while a smaller size difference is associated with a relaxor behaviour.

In order to induce magnetic properties in ferroelectric materials, TTB-type compounds, paramagnetic $\mathrm{Fe}^{3+}$ cations were also introduced in the octahedral framework, for example by a double substitution mechanism $2 \mathrm{Ti}^{4+} \rightarrow \mathrm{Fe}^{3+}+\mathrm{Nb}^{5+}$ [13-20]. It was demonstrated that the ferroelectric and magnetic properties of the $\mathrm{Ba}_{2} \mathrm{LnFeNb}_{4} \mathrm{O}_{15}$ TTBs are directly influenced by the nature of the rare earth, despite the extrinsic origin of the magnetic properties [14]. A correlation appears between cell volume, dielectric ordering temperature and magnetization, which are driven by the size of the rare earth. Moreover the $\mathrm{Ba}_{2} \mathrm{LaFeNb}_{4} \mathrm{O}_{15}$ niobate displays a relaxor behaviour [13] while $\mathrm{Nd}, \mathrm{Sm}$ and Eu substituted niobates constitute a family of room-temperature composite multiferroics. It is thus 
interesting to transfer these original dielectric properties to TTB films and this is the main goal of the present work.

TTB-type films have already been synthesized by various methods, such as RF magnetron sputtering [21,22], sol-gel [23], PLD [24], and MOCVD [25]. Reproducing the chemical complexity of TTB-type materials is the main challenge of thin film growth, along with the transfer of physical properties from bulk to films. It was nevertheless reported in few investigations that TTB films can display approximately the same physical properties as those observed in the bulk. Concerning RF magnetron sputtering, Antsigina et al. reported that the $\mathrm{Ba}_{0.5} \mathrm{Sr}_{0.5} \mathrm{Nb}_{2} \mathrm{O}_{6}$ films are ferroelectric, although with a diffuse phase transition [26]. Michau et al. reproduced the relaxor behaviour of $\mathrm{Ba}_{1+\times / 2} \mathrm{LaNb}_{5-\mathrm{x}} \mathrm{Ti}_{\mathrm{x}} \mathrm{O}_{15} \mathrm{TTBs}$, as observed in ceramics [27].

In the present work, films were deposited on $\mathrm{Pt}(111) / \mathrm{TiO}_{2} / \mathrm{SiO}_{2} / \mathrm{Si}$ substrate by $\mathrm{RF}$ magnetron sputtering from $\mathrm{Ba}_{2} \mathrm{LnFeNb}_{4} \mathrm{O}_{15}$ ceramic targets $(\mathrm{Ln}=\mathrm{La}, \mathrm{Nd}$ and $\mathrm{Eu})$. The $\mathrm{Ba}_{2} \mathrm{LnFeNb}_{4} \mathrm{O}_{15}$ TTBs $(\mathrm{Ln}$ $=\mathrm{La}, \mathrm{Pr}, \mathrm{Nd}, \mathrm{Sm}, \mathrm{Eu}, \mathrm{Gd}$ ) form a rich and versatile family of materials in which original behaviours such as in situ generated multiferroic composites and ferroelectric to relaxor crossovers are encountered [13-17]. After their initial study in polycrystalline form, these materials were grown as single-crystals [28-30] and in the present work, as thin films.

For a better understanding of the context of this study, it is worth recalling some observations concerning the chemical composition of $\mathrm{Ba}_{2} \mathrm{LnFeNb}_{4} \mathrm{O}_{15}$, extracted from previous ceramic and singlecrystal studies. The TTB matrix is reluctant to accommodate the smaller rare earths in the square channels, yielding in some cases to their partial accommodation. In such cases, the TTB framework electroneutrality is maintained by subsequent adjustments of the $\mathrm{Fe} / \mathrm{Nb}$ ratio. The growth of $\mathrm{Ba}_{2} \mathrm{LnFeNb}_{4} \mathrm{O}_{15}$ single crystals confirmed this mechanism [28-30]. Chemical strain and distortions induced by smaller reare earths lead to the evolution of the BLnFN compositions and the occurrence of secondary phases, i.e. $\mathrm{LnNbO}_{4}$ ferguonite and $\mathrm{BaFe}_{12} \mathrm{O}_{19}$ barium ferrite [13,14]. The chemical equilibrium can be depicted as follows:

$\mathrm{Ba}_{2} \mathrm{LnFeNb}_{4} \mathrm{O}_{15} \rightarrow \mathrm{Ba}_{2-\mathrm{x} / 8} \mathrm{Ln}_{1-\mathrm{x}} \mathrm{Fe}_{1-3 \mathrm{x} / 2} \mathrm{Nb}_{4+3 x / 2} \mathrm{O}_{15-\mathrm{x} / 8}+\mathrm{x} \mathrm{LnNbO}_{4}+3 \mathrm{x} / 24 \mathrm{BaFe}_{12} \mathrm{O}_{19}$. The excess of lanthanide oxide reacts with niobium oxide to form fergusonite. To maintain electrical neutrality of the TTB framework, the Fe/Nb ratio is modified in the TTB framework. The subsequent excess of iron oxide reacts with a small amount of barium oxide to form barium ferrite. Thus the ceramics obtained from the stoichiometric composition are composites materials, the multiferroic properties of which can be controlled by chemical and crystal-chemical means [16,17].

In this study, the films were grown from targets with the $\mathrm{Ba}_{2} \mathrm{LnFeNb}_{4} \mathrm{O}_{15}$ composition, in order to evaluate the opportunity to transfer this composite multiferroic system to thin films. Following chemical and structural characterizations, we have investigated their dielectric properties by impedance spectroscopy over a broad temperature and frequency range.

\section{Experiment Details}


Three different films types were grown on the $\mathrm{Pt}(111) / \mathrm{TiO}_{2} / \mathrm{SiO}_{2} / \mathrm{Si}(100)$ (PtS) substrates from stoichiometric $\mathrm{Ba}_{2} \mathrm{LnFeNb}_{4} \mathrm{O}_{15}$ targets with $\mathrm{Ln}=\mathrm{La}$, $\mathrm{Nd}$ and Eu by RF magnetron sputtering (Plassys PM450 - 13.56 MHz) [27]. The films are referred to as BLnFN where $\mathrm{Ln}=\mathrm{La}, \mathrm{Nd}$ or Eu. The targets were prepared through a solid state route from stoichiometric mixtures of $\mathrm{BaCO}_{3}, \mathrm{Fe}_{2} \mathrm{O}_{3}, \mathrm{Nb}_{2} \mathrm{O}_{5}$ and $\mathrm{Ln}_{2} \mathrm{O}_{3}$ and were sintered at $1300^{\circ} \mathrm{C}$ [14]. The PtS substrates were purchased from INOSTEK and a part of them was protected during the films deposition in order to access the bottom electrode. The deposition parameters were optimized regarding both the stabilization of TTB structure and the crystalline quality. The films were deposited at $650{ }^{\circ} \mathrm{C}, 40$ mTorr plasma pressure $\left(\mathrm{O}_{2}=10 \%+\mathrm{Ar}=\right.$ $90 \%$ ), target to substrate distance at $\mathrm{d}=70 \mathrm{~mm}$ and power $100 \mathrm{~W}$ i.e. $5 \mathrm{~W} / \mathrm{cm}^{2}$. X-ray diffraction data in the $\theta-2 \theta$ Bragg-Brentano geometry were recorded on a Philips XPert pro diffractometer $\left(\mathrm{Cu} \mathrm{K \alpha _{1 }}\right.$ radiation, $\lambda=1.54056 \AA$ ) with $10^{\circ}<2 \theta<80^{\circ}$ and step $=0.02^{\circ}$. The film thickness was measured using a Veeco Dektak6M stylus profile mechanical profilometer. Deposition time (5 hours) was adjusted to obtain films thickness about $1 \mu \mathrm{m}$. The films compositions were quantified using the electron probe micro-analysis (EPMA) SX-100 apparatus from CAMECA, without calibration. Electron beam, which typically has probe $150 \mathrm{~nm}$ and energy $5 \mathrm{keV}$, provided a lateral resolution close to $300 \mathrm{~nm}$. The films' compositions were checked by Rutherford Backscattering Spectrometry (RBS) of an alpha particles beam_( $\left.\mathrm{He}^{2+}, 2 \mathrm{MeV}, 15 \mathrm{nA}\right)$ obtained from a HVEE Singletron, at the AIFIRA facility (Centre d'Etudes Nucléaires de Bordeaux-Gradignan, CENBG). Calibration from Ba, $\mathrm{La}, \mathrm{Nd}, \mathrm{Eu}, \mathrm{Fe}, \mathrm{Nb}, \mathrm{Pt}$, Ti and Si pure targets allowed for an accuracy below $5 \%$. Pt Circular dots were deposited ex-situ as a top electrode by dc sputtering through a metal mask at room temperature on the TTB layer. The dot geometry defined the capacitors area: $\mathrm{S}=0.1 \mathrm{~mm}^{2}$. The dielectric properties of capacitors were measured in the metal/insulator/metal configuration, as a function of frequency $(100 \mathrm{~Hz}-1 \mathrm{MHz})$ and temperature $(80 \mathrm{~K}-420 \mathrm{~K})$, using a Hewlett-Packard 4194 impedance analyser with an ac excitation amplitude of $100 \mathrm{mV}$.

\section{Results and Discussion}

\subsection{Chemical characterization of $\mathrm{Ba}_{2} \mathrm{LnFeNb}_{4} \mathrm{O}_{15}$ thin films}

The compositions transferred from the target to the film were investigated by means of Electron-Probe Micro-Analysis (EPMA) and Rutherford BackScattering (RBS). Since oxygen content can hardly be evaluated by these methods, only the cationic ratios are reported here. We obtained the same Ba:Ln:Fe:Nb ratios for La, Eu and Nd based films, i.e 2:1:1:15.5 by EPMA and 2:1:1:12.5 by RBS. These ratios have to be compared with the 2:1:1:4 ratios associated to the $\mathrm{Ba}_{2} \mathrm{LnFeNb}_{4} \mathrm{O}_{15}$ formula. On one hand, the experimental findings show that the $\mathrm{Ba}: \mathrm{Ln}$ and $\mathrm{Ba}: \mathrm{Fe}$ ratios remain quite consistent with the target composition. On the other hand, it appears that $\mathrm{Ba}: \mathrm{Nb}, \mathrm{Ln}: \mathrm{Nb}$ and $\mathrm{Fe}: \mathrm{Nb}$ ratios are much 
lower than expected i.e. there is a $\mathrm{Nb}$ excess in the films. This suggests a difference of sputtering yield between $\mathrm{Nb}$ atoms and the other metallic atoms, as was also observed in other studies [27, 31, 32]. XRD confirmed that the grown films retained the TTB structure, as shown by the XRD patterns of three BLnFN/PtS films with $\mathrm{Ln}=\mathrm{La}, \mathrm{Nd}$ and $\mathrm{Eu}$ and the BNdFN target in Fig. 1a and Fig. 1b, respectively. In the absence of secondary phases as detected by XRD, the excess of $\mathrm{Nb}$ observed in the films could be ascribed to an amorphous phase, the most likely still being niobium oxide $\mathrm{Nb}_{2} \mathrm{O}_{5}$ [32] . This phase has a low permittivity $(\varepsilon=40)$ and should appear as an additional impedance source [33]. However the absence of Nb-rich regions in EPMA mappings does not supports its formation. Thus we can suggest that the niobium excess may be located within the TTB structure itself, with the accommodation of [Nb-O-Nb] chains in its pentagonal channels, as observed by [34] for example. Further investigations dedicated to the study of Nb-content in sputerred TTB thin films are in progress. XRD results are quite similar for the three studied rare earth, the observed peaks position corresponding to polycrystalline, multi-oriented TTB phases, and matching with the targets' XRD patterns and reference data (JCPDS 46-0232, $\mathrm{Ba}_{2} \mathrm{LaNb}_{5} \mathrm{O}_{15}$ ). The main reflections of the ceramic in Fig $1 \mathrm{~b}$ are practically invisible in the films and the (111) reflection is the most intense. This indicates that the films present some degree of preferential orientation along (111), as the $I_{(111)} / I_{(420)}$ intensity ratio is close to 1 while it should be smaller than 0.13 for a fully disoriented film. The intensity ratios vary for each film, meaning that the growth orientation is significantly affected by the composition. To go further, a special attention was paid to impedance spectroscopy analysis, in order to highlight the contribution of TTB phase to the dielectric properties of films 

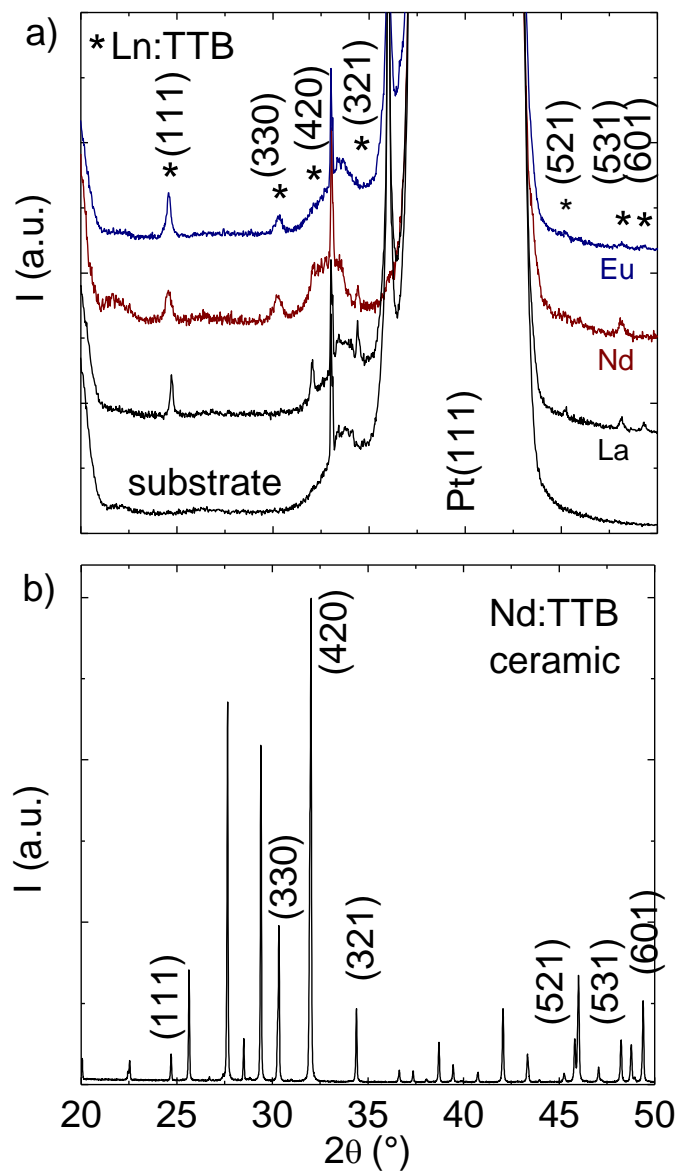

Fig. 1. (Color online) XRD patterns for a) BLnFN films ( $\mathrm{Ln}=\mathrm{La}, \mathrm{Nd}$ and $\mathrm{Eu}$ ) deposited on the $\mathrm{Pt}(111) \mathrm{TiO}_{2} / \mathrm{SiO}_{2} / \mathrm{Si}(100)$ electrode and $\left.\mathrm{b}\right)$ the $\mathrm{BNdFN}$ target

\subsection{Dielectric characterization of $\mathrm{Ba}_{2} \mathrm{LnFeNb}_{4} \mathrm{O}_{15}$ thin films: Maxwell Wagner relaxation}

To evidence the contribution of the TTB phase, the complex impedance of the films was investigated. Nyquist plot obtained at $350 \mathrm{~K}$ is shown in Fig 2a for the Pt/BNdFN/PtS capacitor. A large semicircle is displayed in the $-Z$ " vs Z' plot, with the shoulder in the higher frequency range showing the presence of a second semicircle (see inset Fig 2a). Better insight on both dielectric responses is provided by the plot of the electric modulus M" versus frequency (Fig 2b) [35]. At $350 \mathrm{~K}$ M" spectra displays a small peak at $1 \mathrm{kHz}$ and a large peak at $70 \mathrm{kHz}$, which are related to the two semicircles observed in Fig 2a. Thus, impedance data can be modelled and analyzed using an equivalent circuit with two parallel $\mathrm{R}_{1} \mathrm{C}_{1}$ and $\mathrm{R}_{2} \mathrm{C}_{2}$ elements, in series, each corresponding to one of the observed semicircles. As temperature decreases from $350 \mathrm{~K}$ to $300 \mathrm{~K}$, Both M" peaks shift toward lower frequencies. Their intensities remain almost constant indicating that the effective permittivity for each response is unchanged. Permittivities $\varepsilon_{1}$ and $\varepsilon_{2}$ and conductivities $\sigma_{1}$ and $\sigma_{2}$ can be extracted from 
relations of complex impedance and $\mathrm{R}_{1} \mathrm{C}_{1}$ and $\mathrm{R}_{2} \mathrm{C}_{2}$ elements [3]. We obtained $\varepsilon_{1} \sim 700$ and $\varepsilon_{2} \sim 150$. On the one hand $\varepsilon_{2}$ is close to the permittivity of the corresponding BNdFN ceramic [14] and can be identified as the permittivity of bulk, i.e. $\varepsilon_{\mathrm{b}}=\varepsilon_{2}$. The higher conductivity of bulk, $\sigma_{\mathrm{b}}=\sigma_{2} \sim 10^{-6} \Omega^{-1} . \mathrm{cm}^{-1}$ at $300 \mathrm{~K}$, indicates the presence of semiconductive grains. The analysis of $\sigma_{\mathrm{b}}$ shows that the bulk conductivity is thermally activated, and follows a straightline relationship in an Arrhenius scale, with a characteristic activation energy $\mathrm{E}_{\mathrm{a}} \sim 0.30 \mathrm{eV}$. On the other hand the high value of $\varepsilon_{1}$ excludes a dielectric response from an amorphous $\mathrm{Nb}_{2} \mathrm{O}_{5}$ oxide, and should involve a mechanism of barrier layer capacitors which will be further discussed later. This observation thus supports the formation of a single phased film.
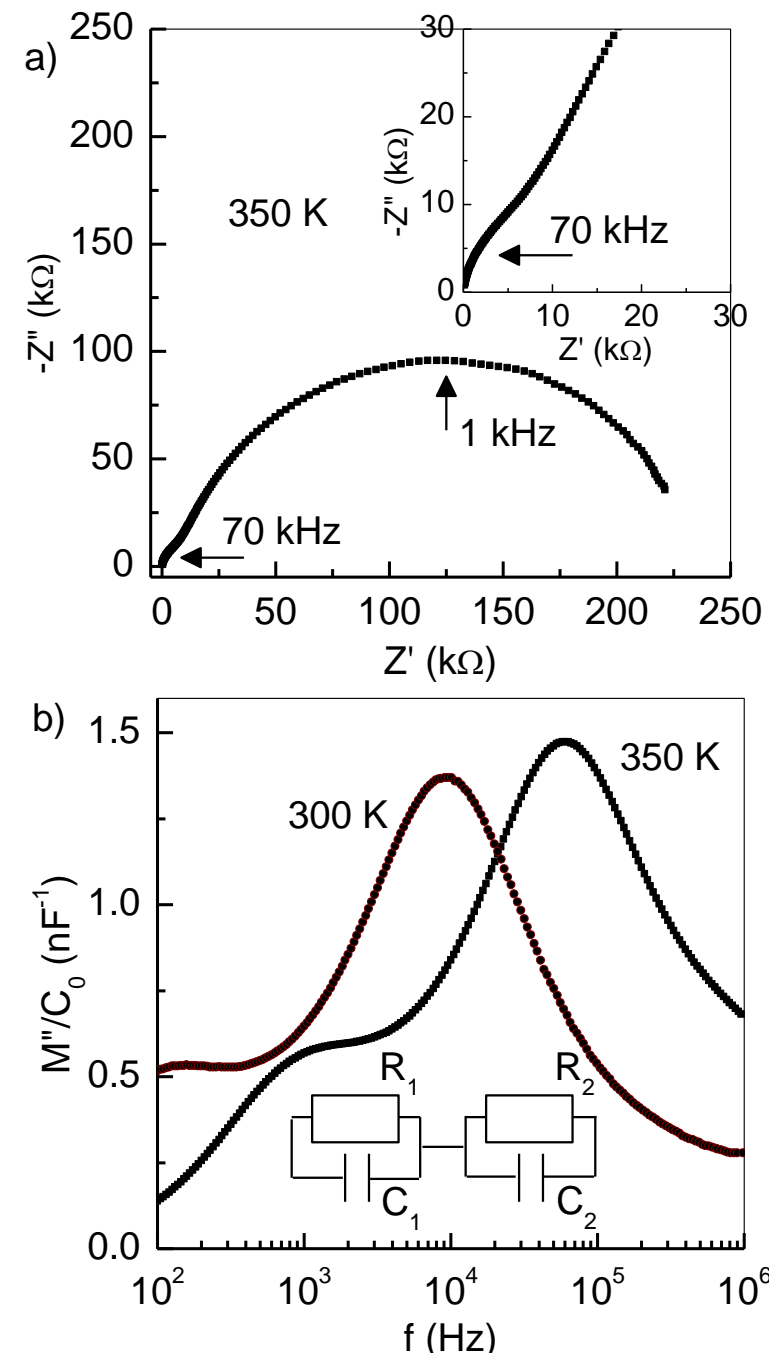

Fig. 2. (Color online) Complex impedance plot at $350 \mathrm{~K}$ (a) and M'' spectroscopy plot at two temperatures $300 \mathrm{~K}$ and $350 \mathrm{~K}$ (b) for the BNdFN film 
The complex permittivity $\varepsilon^{*}=\varepsilon^{\prime}+\mathrm{j} \varepsilon$ " was extracted from impedance measurements. Dielectric loss $\tan \delta$ and conductivity $\sigma^{\prime}$ are related to the complex permittivity through the relations $\tan \delta=\varepsilon " / \varepsilon$ ' and $\sigma=\varepsilon " \omega$ ( $\omega$ is the angular frequency), respectively. The frequency dependence of dielectric permittivity and losses for BNdFN films were investigated at various temperatures and are shown in Fig 3a and 3b, respectively. At high temperatures and low frequencies, the permittivity reaches a value $\varepsilon^{\prime}=\varepsilon_{1}=800$ and drops to $\varepsilon^{\prime}=\varepsilon_{2}=150$ at higher frequencies. The relaxation in $\varepsilon^{\prime}$ is accompanied by a peak in $\tan \delta$, which shifts to lower frequencies when the temperature decreases (Fig 3b). Below $200 \mathrm{~K}$, only the bulk response is visible over the whole frequency range, while permittivity and losses become smaller, i.e. $\varepsilon^{\prime} \sim 100$ and $\tan \delta \sim 2 \%$.
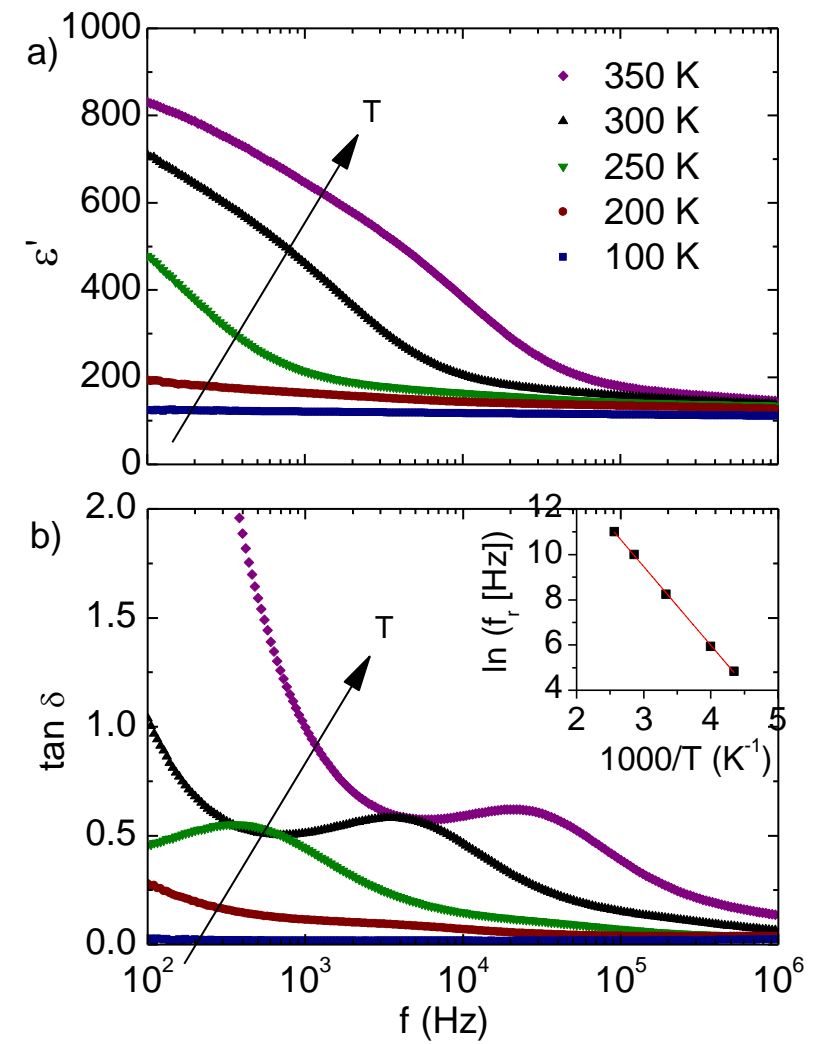

Fig. 3 (Color online) Frequency dependence of (a) the effective dielectric constant $\varepsilon$ ' and (b) the dielectric loss $\tan \delta$ for the BNdFN film at various temperatures. Inset shows the MW relaxation frequency in an Arrhenius law

The temperature dependence of the relaxation indicates a thermally activated mechanism. The relaxation frequency follows an Arrhenius law with $\mathrm{Ea} \sim 0.30 \mathrm{eV}$ (Table 1). Ion jump polarization may explain this relaxation mechanism, as it is frequently found in polycrystalline dielectrics encompassing ion vacancies. However, activation energy similar to that of the bulk resistivity corroborates a relaxation governed by the bulk, and thus Maxwell Wagner (MW) type contributions [36]. Indeed, MW relaxation is significant in samples with semiconductive grains because of the 
formation of barrier layer capacitors in the region close to the metallic electrodes [37] and/or the grain boundaries [38]. Stable space charges regions called depletion layers are formed at interfaces and lead to high capacitive and resistive effects. The barrier layers act as an extrinsic source of impedance connected in series to the bulk. Given $R_{1} \gg R_{2}$ and $C_{1} \gg C_{2}$, their contributions on the dielectric response are visible on characteristic ranges of frequency, i.e. $\omega=(\mathrm{RC})^{-1}$ and the barrier layers dominate at low frequency while the bulk appears at high frequency. In this case, the time constant $\tau$ follows approximatively $\tau=\mathrm{R}_{2} \mathrm{C}_{1}$. Thus, assuming that $\mathrm{C}_{1}$ is nearly constant with the temperature, the time constant is essentially driven by the conductivity of grains.

Table 1. Activation energies $E_{a}$ of the Maxwell-Wagner relaxation and relaxor behaviour at low temperature versus BLnFN ( $\mathrm{Ln}=\mathrm{La}, \mathrm{Nd}$ and $\mathrm{Eu})$ as deposited, the post annealed BNdFN films and the BEuFN ceramic.

\begin{tabular}{lcc}
\hline & Maxwell-Wagner $\mathrm{E}_{\mathrm{a}}(\mathrm{eV})$ & Relaxor $\mathrm{E}_{\mathrm{a}}(\mathrm{eV})$ \\
\hline BLaFN & - & $0.31(0.07)$ \\
BNdFN & $0.30(0.03)$ & - \\
BNdFN & - & $0.34(0.04)$ \\
post-ann. & & \\
BEuFN & $0.33(0.04)$ & $0.30(0.05)$ \\
BEuFN & - & $0.17(0.02)$ \\
ceramic & & \\
\hline
\end{tabular}

The frequency dependence of $\varepsilon^{\prime}, \tan \delta$ and $\sigma^{\prime}$ for Pt/BLnFN/PtS stacks (with Ln $=\mathrm{La}$, Nd and $\mathrm{Eu}$ ) are shown in Fig 4a, $4 \mathrm{~b}$ and $4 \mathrm{c}$, respectively. At high frequencies, i.e. $\mathrm{f}=1 \mathrm{MHz}$, the three films display similar bulk permittivities. As the frequency decreases below $10 \mathrm{kHz}$, a large increase of $\varepsilon^{\prime}$ is observed for BNdFN and BEuFN films, accompanied by a peak in $\tan \delta$ and a relaxation in $\sigma$. The permittivity remains constant over the whole frequency range for BLaFN film. The conductivity for both BNdFN and BEuFN films is higher than for the BLaFN film. 

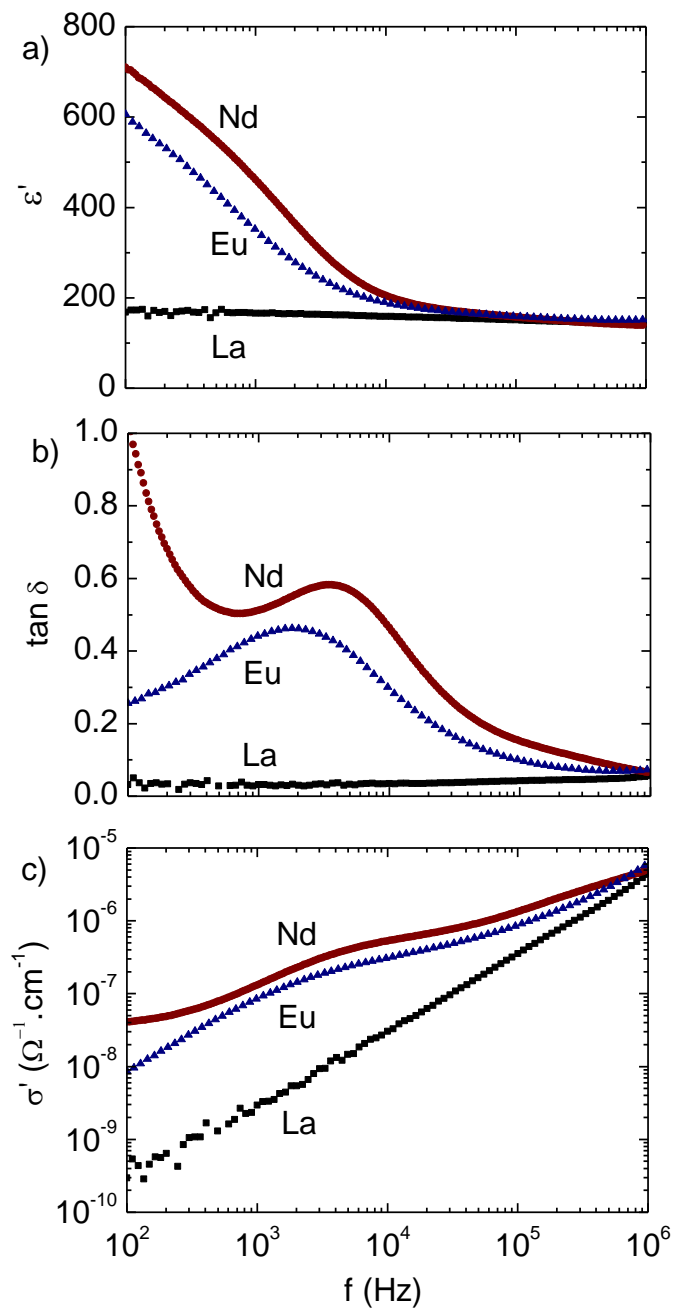

Fig. 4 (Color online) Frequency dependence of (a) the effective dielectric constant $\varepsilon^{\prime}$, (b) the dielectric loss $\tan \delta$ and (c) the conductivity $\sigma$ ' for the BLnFN films ( $\mathrm{Ln}=\mathrm{La}, \mathrm{Nd}$ and $\mathrm{Eu}$ ) at room temperature

Temperature-dependent studies of the BEuFN film revealed that the relaxation is also thermally activated, with $\mathrm{Ea}=0.33 \mathrm{eV}$, close to the activation energy found in BNdFN film (Table 1). Thus, it appears that the rise of the conductivity is due to the same phenomenon in both BNdFN and BEuFN films. This phenomenon could be related to the one observed in corresponding ceramics and singlecrystals, in which the insertion of smaller rare earths (i.e. $\mathrm{Nd}$ or Eu instead of La) leads to and offstoichiometry that could involve oxygen losses, which can be induced during the processing [14,30,31]. It was reported that the leakage current of oxide films could be reduced by activated oxygen annealing [39]. Considering these results, and in order to evidence an effect of oxygen vacancies, the BNdFN film was ex-situ annealed under oxygen atmosphere at the deposition temperature. XRD (not shown) confirmed the preservation of the TTB structure and the absence of structural changes following the post-annealing process. For both the as-deposited and the post annealed BNdFN films, frequency dependence of the dielectric constant and the conductivity are shown in Fig $5 \mathrm{a}$ and $5 \mathrm{~b}$, respectively. The relaxation disappears after the post-annealing process, while 
the film displays a lower conductivity, which drops from $\sigma \sim 5.10^{-7} \Omega^{-1} \cdot \mathrm{cm}^{-1}$ to $\sigma \sim 8.10^{-8} \Omega^{-1} . \mathrm{cm}^{-1}$ at $10 \mathrm{kHz}$. This is similar to the conductivity of bulk ceramics [14], and in agreement with the higher conductivity of as deposited samples being induced by a slight oxygen deficiency. In the range [5 kHz $-1 \mathrm{MHz}$, the conductivity increases with the frequency (Fig $5 \mathrm{~b}$ ), and can be described by the universal dielectric response $\sigma=\sigma_{\mathrm{dc}}+\sigma_{\mathrm{ac}} \omega^{\mathrm{n}}$ ( $\sigma \mathrm{dc}$ is the dc conductivity of bulk, $\sigma_{\mathrm{ac}}$ is a constant and $\mathrm{n}$ is a parameter having a value between 0 and 1) [36]. The bulk dc conductivity is visible at intermediate frequencies on the as deposited sample while the bulk ac conductivity dominates at higher frequencies. For the annealed sample, the dc conductivity is not visible in this frequency range and its response is described only by the frequency-dependent bulk ac conductivity $\sigma \sim \omega^{\mathrm{n}}$. This type of variation is often observed in disordered systems and is attributed to hopping transport between localized states close to Fermi level [40]. In the investigated sample, the statistical distribution of $\mathrm{Fe}^{3+}$ and $\mathrm{Nb}^{5+}$ within the octahedral framework could trigger such a mechanism [41].
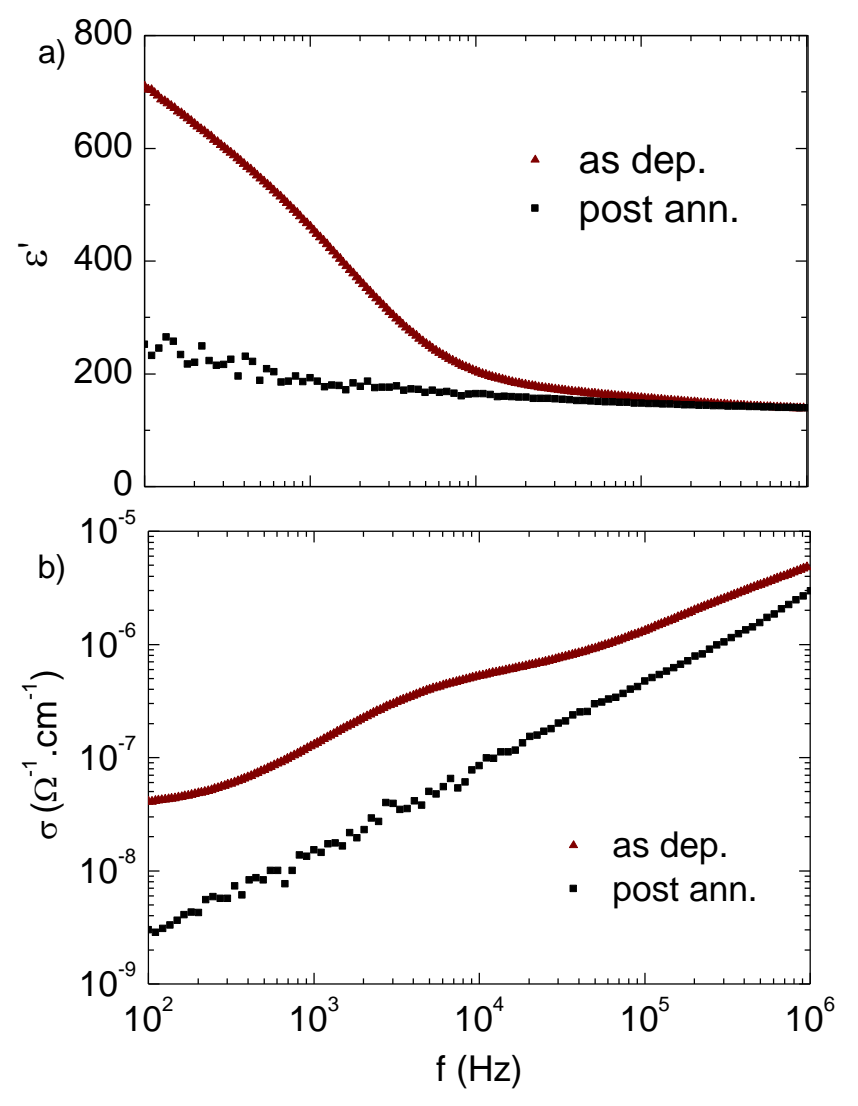

Fig. 5 (Color online) Frequency dependence of the dielectric constant $\varepsilon^{\prime}$ (a) and the conductivity $\sigma^{\prime}$ (b) for both as-deposited and post annealed BNdFN films at room temperature

\subsection{Dielectric characterization of $\mathrm{Ba}_{2} \mathrm{LnFeNb}_{4} \mathrm{O}_{15}$ thin films: Dielectric anomaly}


The temperature dependence of the dielectric properties was investigated on a post annealed BNdFN film. The frequency-dependence of the dielectric permittivity is shown at various temperatures in Fig 6. At $100 \mathrm{~K}, \varepsilon^{\prime}$ is constant over the whole frequency range and corresponds to bulk permittivity. Upon increasing the temperature from $100 \mathrm{~K}$ to $260 \mathrm{~K}$, the permittivity increases from 100 to 150 . When raising the temperature to $420 \mathrm{~K}$, the permittivity further increases at lower frequencies, as the capacitive response of the barrier layer appears. Meanwhile, the permittivity remains almost constant at higher frequencies, whatever the temperature.

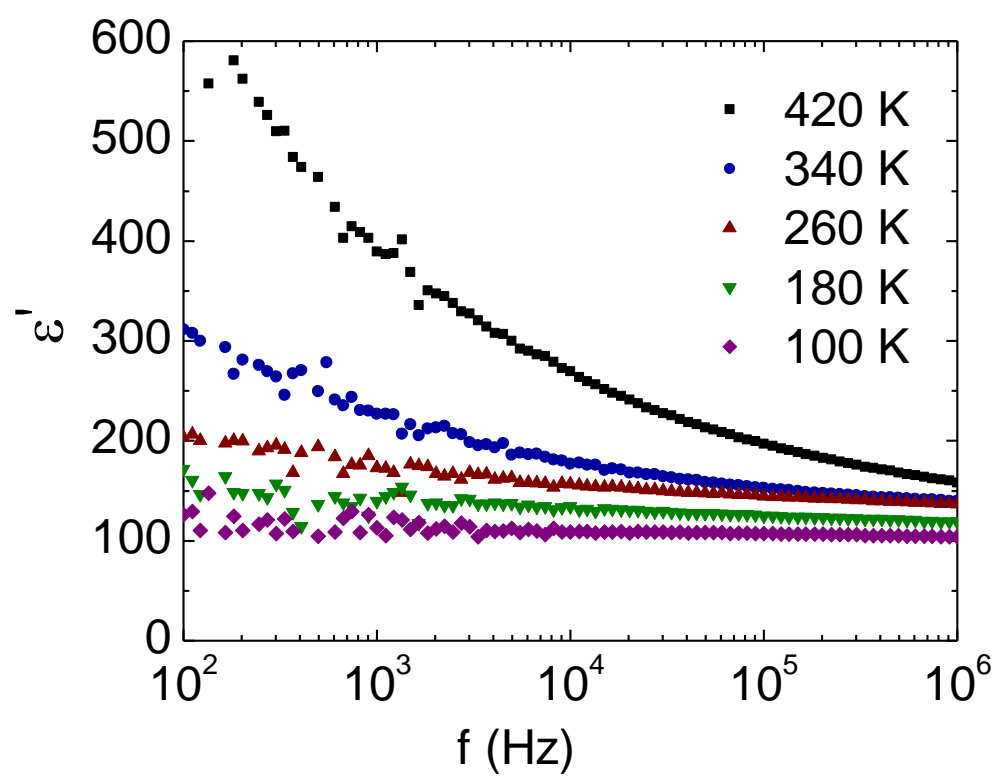

Fig. 6 (Color online) Frequency dependence of the dielectric constant $\varepsilon$ ' for post annealed BNdFN film at various temperatures

An anomalous behaviour of the bulk permittivity with temperature is evidenced from the plot of the dielectric constant and the dielectric losses at various frequencies for the post annealed BNdFN film (Fig 7). Three regimes are evidenced in Fig 7: (1) increasing of bulk permittivity at lower temperatures (2) plateau of the bulk permittivity at intermediate temperature and (3) increasing of the apparent permittivity due to the effect of barrier layer capacitors at higher temperatures. In addition, the dielectric anomaly in $\varepsilon(T)$ is transferred into a peak in $\tan \delta(T)$. This peak shifts to higher temperatures as frequency increases. From several frequency scans, we conclude that this dielectric anomaly is not related to a static phenomenon, but is of purely dynamic origin.

Tetragonal tungsten bronzes are known to exhibit a series of dielectric anomalies, especially at low temperature [42]. For the greater part, they are explained by either ferroelectric or relaxor behaviour, which could be driven by the size of the ions inserted in the TTB framework $[43,44]$. As indicated by Fig 7, the frequency dispersion excludes a normal ferroelectric behaviour. For a better insight into the films dielectric behaviour, pyroelectric and piezoeletric measurements have to 
be considered since such signals are expected from relaxor compounds. However, it is important to note that in ceramics, a diffuse dielectric anomaly is observed at low temperature for all compounds $\mathrm{Ba}_{2} \mathrm{LnFeNb}_{4} \mathrm{O}_{15}$ with $\mathrm{Ln}=\mathrm{La}, \mathrm{Pr}, \mathrm{Nd}, \mathrm{Sm}$ and $\mathrm{Eu}$ [13-17]. Thus one may consider that these dielectric anomalies originate from the same phenomenon in both ceramics and films. In fact, these anomalies were observed in the $\mathrm{BLaFN}$ and $\mathrm{BEuFN}$ films in temperature ranges similar to those of ceramics. However, because of a restricted frequency range, no reliable fit of the experimental data using the Vogel-Fulcher relationship could be performed, and thus no accurate Vogel-Fulcher freezing temperature $\mathrm{T}_{\mathrm{VF}}$ could be determined. Thus, the activation energy was extracted from an Arrhenius fit, and found similar in all films, $\mathrm{E}_{\mathrm{a}} \sim 0.30 \mathrm{eV}$ (table 1), indicating that the relaxation mechanism in our BLnFN films is relatively independent from the size of rare earth ions. Although anomalies appear quite similar, there is some difference in activation energies of ceramics, i.e, $\mathrm{E}_{\mathrm{a}}=0.17 \mathrm{eV}$ in BEuFN ceramics (table 1) and the activation energies varies with the size of rare earth. Michau et al. showed in a previous paper that the relaxor behaviour of $\mathrm{Ba}_{1+\mathrm{x} / 2} \mathrm{LaNb}_{5-\mathrm{x}} \mathrm{Ti}_{\mathrm{x}} \mathrm{O}_{15}$ films was driven by the $(\mathrm{Ba}+\mathrm{La}) /(\mathrm{Nb}+\mathrm{Ti})$ cationic ratio [27]. Thus, the deviation from the stoichiometry in our films may also act as major parameter on their activation energies.
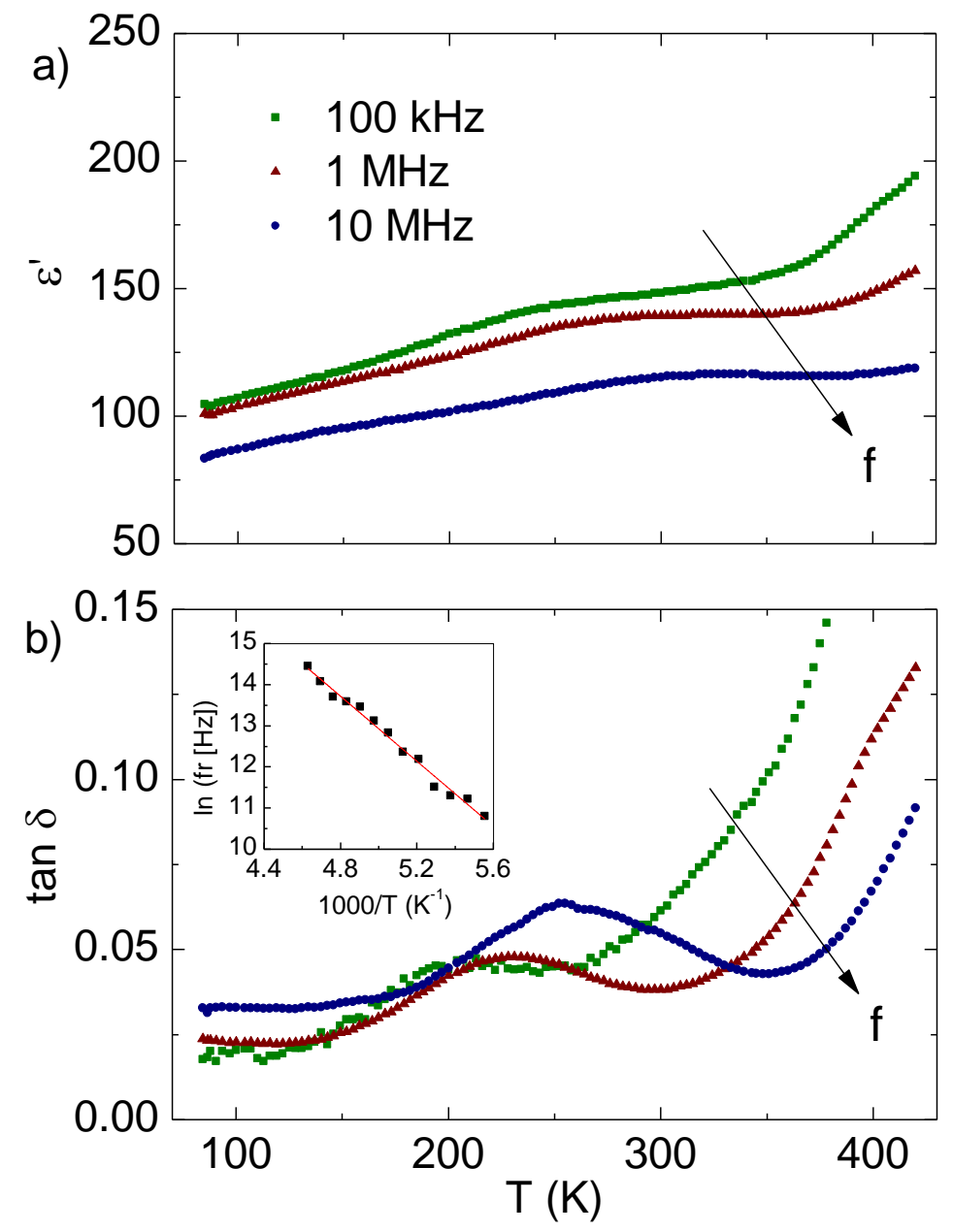
Fig. 7 (Color online) Temperature dependence of the dielectric constant $\varepsilon$ ' (a) and the dielectric loss $\tan \delta$ (b) for the post annealed BNdFN film at various frequency. Inset shows the relaxation frequency in an Arrhenius law.

One may wonder if oxygen vacancies are involved in these low temperature anomalies. For such a purpose, more detailed studies were performed on $\mathrm{Nd}$ films, to obtain some insights on the role of oxygen content. The temperature dependence of the dielectric constant and the dielectric loss for the as-deposited and post annealed films are compared in Fig $8 \mathrm{a}$ and $8 \mathrm{~b}$, respectively. The dielectric anomaly is visible in both as deposited and post annealed samples. However it is more pronounced following the post annealing, suggesting that oxygen vacancies are not responsible for the dielectric anomaly observed at low temperature but may hinder it. This dielectric anomaly may be related to offcenter barium or rare earth ions displacements for example, which could be influenced by some oxygen vacancies. Thus, the dielectric anomaly observed at low temperature is likely related to the TTB phase stabilized in the films, and further investigation is needed to assess the mechanisms involved in its apparition.
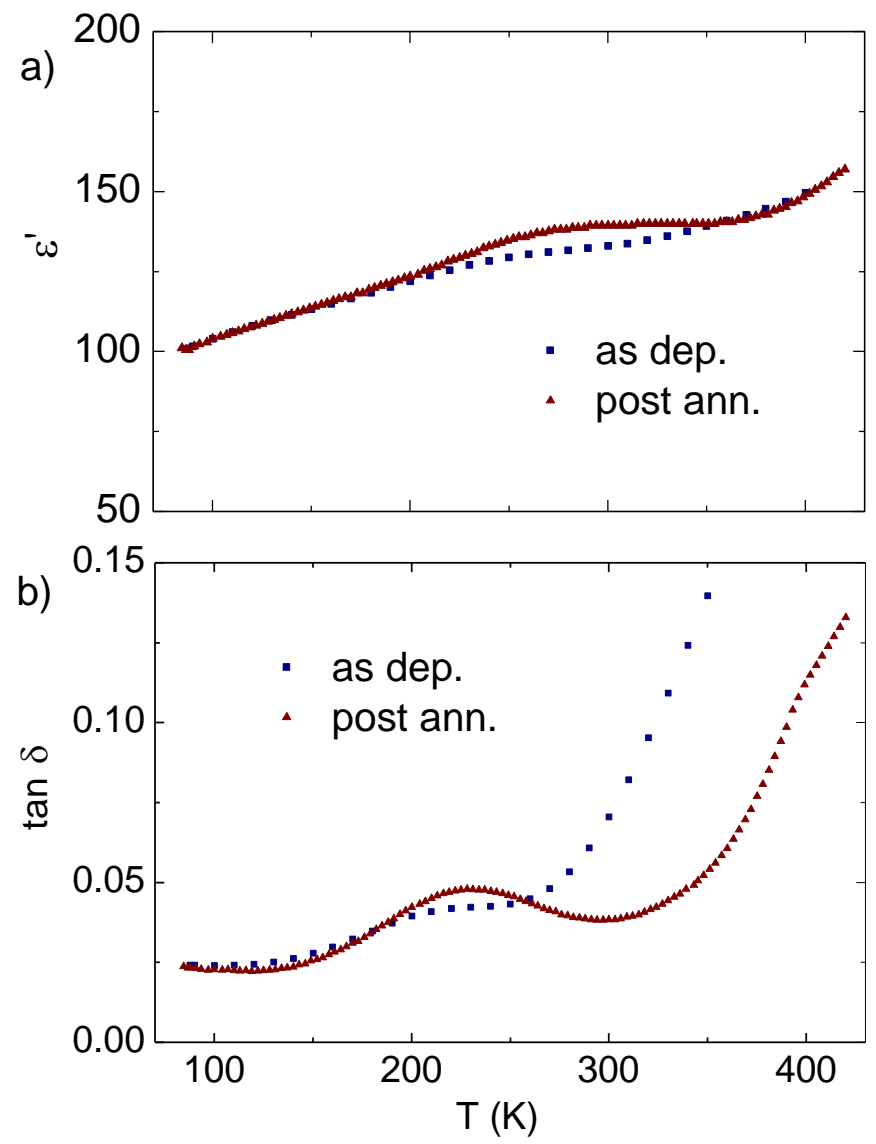

Fig. 8 (Color online) Temperature dependence of the dielectric constant $\varepsilon$ ' (a) and the dielectric loss $\tan \delta$ (b) for both as-deposited and post annealed BNdFN films at $1 \mathrm{MHz}$ 


\section{Conclusion}

Tetragonal tungsten bronze films from $\mathrm{Ba}_{2} \mathrm{LnFeNb}_{4} \mathrm{O}_{15}(\mathrm{Ln}=\mathrm{La}, \mathrm{Nd}$ and $\mathrm{Eu})$ ceramic targets were deposited by RF magnetron sputtering on $\mathrm{Pt} / \mathrm{TiO}_{2} / \mathrm{SiO}_{2} / \mathrm{Si}$ substrates. The dielectric properties are similar to those of the bulk with $\varepsilon \sim 150$ and $\sigma \sim 10^{-6} \Omega^{-1} . \mathrm{cm}^{-1}$ at $1 \mathrm{MHz}$ and at room temperature. Two dielectric anomalies with similar activation energies were observed in the films with an obvious effect of post annealing under oxygen for one of them. It can be concluded that the high temperature anomaly results from a MW-type mechanism while the low-temperature anomaly is likely related to a relaxor behaviour which is also observed in ceramics. Further developments of this work include the investigation of the mechanisms involved in the dielectric response of the films at low temperature, and its comparison to similar responses observed in bulk samples, whether ceramics or single-crystals.

\section{Acknowledgments}

We thank S. Sorieul from CENBG in Bordeaux for the RBS measurements. This project was supported by the French Agency for Research under contract ANR CROCRODIEL (ANR-09-JCJC0079). 


\section{References}

[1] L.W. Martin, Y.-H. Chu, R. Ramesh, Mater. Sci. and Eng. R. 68 (2010) 89.

[2] A. M. dos Santos, S. Parashar, A. R. Raju, Y. S. Zhao, A. K. Cheetham, C. N. Rao, Solid State Commun. 122 (2002) 49.

[3] K. L. Ngai, T. L. Reinecke, Phys. Rev. Lett. 38 (1977) 74.

[4] J. E. Geusic, H. J. Levinstein, J. J. Rubin, S. Singh, L.G. Van Uitert, App. Phys. Lett. 11 (1967) 269.

[5] S. Ando, K. Konakahara, S. Okamura, T. Tsukamoto, J. Eur. Ceram. Soc. 19 (1999) 1369.

[6] A. M. Glass, J. App. Phys. 40 (1969) 4699.

[7]P. H. Fang, R. S. Roth, J. Appl. Phys. 31 (1960) S278.

[8] K. Masuno, J. Phys. Soc. Jpn 19 (1964) 323.

[9] X. M. Chen, G. L. Lü, J. S. Yang, Y. J. Wu, J. Solid State Chem. 148 (1999) 438.

[10] C. A. Kirk, M. C. Stennett, I. M. Reaney, A. R. West, J. Mater. Chem. 12 (2002) 2609.

[11] A. Simon, J. Ravez, Phys. Status Solidi A 199 (2003) 541.

[12] X. L. Zhu, X. M. Chen, X. Q. Liu, X. G. Li, J. App. Phys. 105 (2009) 124110.

[13] E. Castel, Synthèse de Nouveaux Matériaux Multiferroïques au Sein de la Famille des Bronzes Quadratiques de Formule $\mathrm{Ba}_{2} \mathrm{LnFeNb}_{4} \mathrm{O}_{15}$ ( $\mathrm{PhD}$ thesis, Bordeaux, 2009).

[14] M. Josse, O. Bidault, F. Roulland, E. Castel, A. Simon, D. Michau, R. Von der Mühll, O. Nguyen, M. Maglione, Solid State Sci. 11 (2009) 1118.

[15]E. Castel, M. Josse, D. Michau, M. Maglione, J. Phys.: Condens. Matter 21 (2009) 452201.

[16] E. Castel, M. Josse, F. Roulland, D. Michau, L. Raison, M. Maglione, J. Magn. Magn. Mater. 321 (2009) 1773.

[17]F. Roulland, M. Josse, E. Castel, M. Maglione, Solid State Sci. 11 (2009) 1709.

[18]E. E. McCabe, A. R. West, J. Solid State Chem. 183 (2010) 624.

[19] Y. J. Wu, Z. J. Hong, Y. Q. Lin, S. P. Gu, X. Q. Liu, X. M. Chen, J. App. Phys. 108 (2010) 014111.

[20] L. Fang, X. Peng, C. Li, C. Hu, B. Wu, H. Zhou, J. Am. Ceram. Soc. 93 (2010) 2430.

[21] V. G. Zhdanov, E. G. Kostsov, V. K. Malinovsky, L. D. Pokrovsky, L. N. Sterelyukhina, Ferroelectrics 29 (1980) 219.

[22] Y. Masuda, H. Masumoto, A. Baba, T. Goto, T. Hirai, Jpn J. Appl. Phys. 32 (1993) 4043.

[23] Y. Xu, C. J. Chen, R. Xu, J. D. Mackenzie, Phys. Rev. B 44 (1991) 35.

[24] S. S. Thony, K. E. Youden, J. S. Harris, L. Hesselink, Appl. Phys. Lett. 65 (1994) 2018.

[25] M. J. Nystrom, B. W. Wessels, W. P. Lin , G. K. Wong, D. A. Neumayer, T. J. Marks, Appl. Phys. Lett. 66 (1995) 1726.

[26] V. D. Antsigin, E. G. Kostosov, V. K. Malinovsky, L. N. Sterelyukhina, Ferroelectrics 38 (1981) 761.

[27] D. Michau, A. Simon, M. Maglione J. Phys. D 42 (2009) 075407. 
[28] E. Castel, P. Veber, M. Albino, M. Velazquez, S. Pechev, D. Denux, J.P. Chaminade, M.

Maglione, M. Josse J. Cryst. Growth 340 (2012) 156.

[29] M. Albino, P. Veber, E. Castel, M. Velazquez, K. Schenk, G. Chapuis, M. Lahaye, S. Pechev, M. Maglione, M. Josse, Eur. J. Inorg. Chem. 15 (2013) 2817.

[30] M. Albino, P. Veber, S. Pechev, C. Labrugère, M. Velazquez, M. Maglione, M. Josse, Cryst Growth \& Des. 14 (2014) 500.

[31] M. Cuniot-Ponsard, J. M. Desvignes, B. Ea-Kim, E. Leroy, J. Appl. Phys. 93 (2003) 1718.

[32] K. Bockute, G. Laukaitis, D. Milcius, Surf. Coatings Technol. 214 (2013) 97.

[33] N. Fuschillo, B. Lalevic, N.K. Annamalai, 1975 Thin Solid Films 30 (1975) 145.

[34] M.M. Ftini, B. Ayed, A. Haddad, J. Chem. Cryst. 33 (2003) 123.

[35] D.C. Sinclair, A.R. West, J. Appl. Phys. 66 (1989) 3850.

[36] A. K. Jonscher, Dielectric Relaxations in Solids (Chelsea Dielectric Press, London, 1983).

[37] R. Bodeux, M. Gervais, J. Wolfman, C. Autret-Lambert, G. Liu, F. Gervais Thin Solid Films 520 (2012) 2632.

[38] T. B. Adams, D. C. Sinclair, A. R. West, Phys. Rev. B 73 (2006) 094124.

[39] J-H Joo, J-M Seon, Y-C Jeon, K-Y Oh, J-S Roh, J-J Kim, Appl. Phys. Lett. 70 (1997) 3053.

[40] D. Emin, Electronic and Structural Properties of Amorphous Semiconductors (P.G. Le Comber and J. Mort, New York, 1972).

[41] Z. Abdelkafi, N. Abdelmoula, H. Khemakhem, O. Bidault and M. Maglione, Journal of Applied Physics 100 (2006) 114111.

[42] C Filipic, Z Kutnjak, R Lortz, A Torres-Pardo, M Dawber and J. F. Scott J. Phys. Condens. Matter 19 (2007) 236206.

[43] M. C. Stennett, I. M. Reaney, G. C. Miles, D. I. Woodward, and A. R. West, C. A. Kirk, and I. Levin, J. App. Phys. 101 (2007) 104114.

[44] A. Simon and J. Ravez, C. R. Chimie 9 (2006) 1268. 


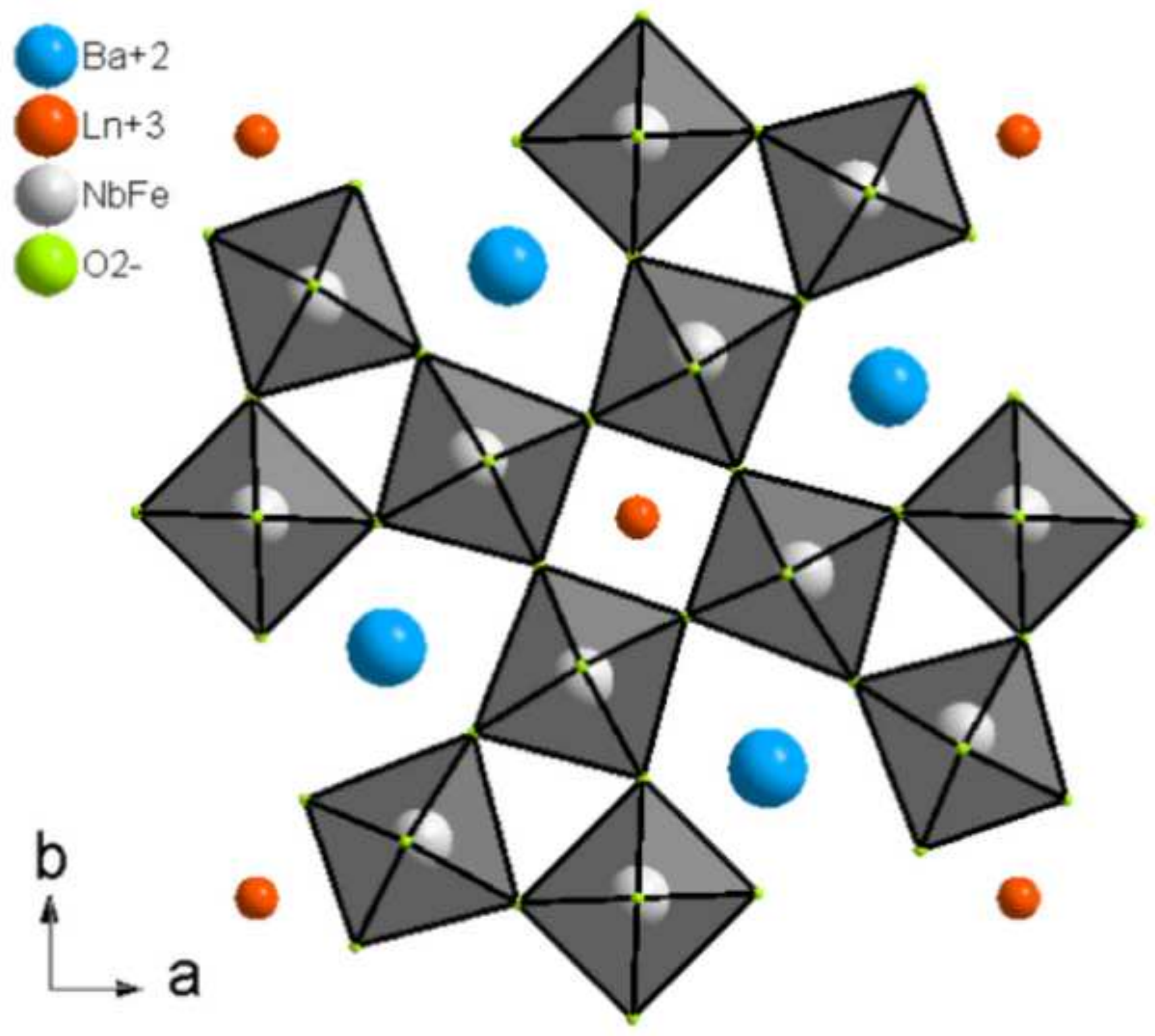

